IOSR Journal of Engineering (IOSRJEN)

e-ISSN: 2250-3021, p-ISSN: 2278-8719

Vol. 3, Issue 9 (September. 2013), ||V1\| PP 32-38

\title{
Analysis for critical radius of insulation for a cylinder.
}

\author{
Prof.N.B.Totala, Anant A.Paralkar,Nikhil R.Kakade, Kunal R.Kawthekar, \\ Shashank R.Borde \\ ${ }^{I}$ (Assistant Professor, Department of Mechanical Engineering,MIT Academy of Engineering,Alandi (D), Pune, \\ Maharashtra, 412105) \\ 2,3,4\&5 (Department of Mechanical Engineering, MIT Academy of Engineering, Alandi(D), Pune, Maharashtra, \\ 412105)
}

\begin{abstract}
The critical radius effect is an interesting phenomenon of heat transfer in insulated circular solids. Insulating a cylinder or sphere larger than the critical radius has the expected effect of retarding heat loss. If the radius of cylinder or sphere is smaller than the critical radius, adding insulation will actually increase heat loss. In present paper a copper cylinder is heated by means of a heater $300 \mathrm{~W} 240 \mathrm{~V}$ which heats uniformly the copper cylinder. This copper cylinder is bounded by asbestos. By heating of copper cylinder asbestos gets heated.Tappings for thermocouple are given along insulation for asbestos. Finally critical radius of insulation for a cylinder is determined.
\end{abstract}

Keywords: - Heat transfer co-efficient, Nusseltnumber, Radius of Insulation, Raleighnumber, Thermal conductivity.

\section{NOMENCLATURE}

Bi -Biot number, (dimensionless)

$\mathrm{h}$-convective heat transfer coefficient $\left(\mathrm{W} / \mathrm{m}^{2} \mathrm{~K}\right)$

$\mathrm{k}$-thermal conductivity of insulating material $(\mathrm{W} / \mathrm{mK})$

L- Length of the cylindrical radial system $(\mathrm{m})$

$\mathrm{Q}_{\text {bare- }}$ rate of heat transfer from the bare radial system (W)

$\mathrm{q}_{\mathrm{ins}}-$ rate of heat transfer from the insulated radial system (W)

$\mathrm{r}_{\mathrm{i}}$-inner radius of the insulation $(\mathrm{m})$

$\mathrm{r}_{\mathrm{o}}$ - outer radius of the insulation $(\mathrm{m})$

Ro -dimensionless radii of the insulation

$\mathrm{R}_{\text {critical- }}$ critical radius (m)

$\mathrm{Q}_{\text {conv-Rate }}$ of heat transfer by natural convection

$\mathrm{r}_{\mathrm{cr}-\text { Critical radius of insulation }(\mathrm{m})}$

Tm-. Mean film Temperature $\left({ }^{\circ} \mathrm{c}\right)$

$\beta$-. Coefficient of Volumetric Expansion $\left(\mathrm{K}^{-1}\right)$

RaD-Raleigh Number

Nu-Empirical correction for Nusselt number of natural convection for Horizontal cylinder

Q-Rate of heat transfer for insulated cylinder

L=Length $(\mathrm{m})$

Pr-Prandtl Number

Cp-Specific Heat $(\mathrm{J} / \mathrm{Kg} \mathrm{K})$

To-Ambient temperature

\section{INTRODUCTION}

The science of thermodynamics deals with the amount of heat transfer as system undergoes a process from one equilibrium state to another, and makes no reference to how long the process will take. Heat has always been perceived to be something that produces sensation of warmth, and one would think that the nature of heat is one of the first things understood by mankind. But it was only in the middle of the nineteenth century that we had a true physical understanding of the nature of heat, thanks to the development at that time of the kinetic theory, which treats molecules as tiny balls that are in motion and thus possess kinetic energy. Heat is then defined as the energy associated with the random motion of atoms and molecules.

The critical radius effect is an interesting phenomenon of heat transfer in insulated solids. Insulating a cylinder or sphere larger than the critical radius has the expected effect of retarding heat loss. If the radius of cylinder or sphere is smaller than the critical radius, adding insulation will actually increase heat loss .The additional insulation increases the conduction resistance of the insulation layer but decreases the convection 
resistance of the surface because of the increase in the outer surface area for convection. Therefore the net heat transfer from the pipe may increase or decrease, depending on which effect dominates. Critical radius is independent of radius of circular pipe/tube. It depends on conductivity of insulation ' $\mathrm{k}$ ' and the convective heat transfer coefficient ' $h$ ', between exposed surface of insulation and its surroundings. The value of the critical radius ' $r_{c}$ ' will be the largest when conductivity of insulation ' $k$ ' is large and convection heat transfer ' $h$ ' is small. There are several unit operations and unit processes which operate at high temperatures. Flow of heat is important to attain uniform temperature in the furnace chamber. Ideally the available heat must be utilized to raise the temperature of the reactants and products to the desired value, but some amount of heat is always lost to the surrounding. Loss of heat to the surrounding is loss of energy and one of the main objectives of an engineer is to minimize the heat losses. Fundamentals of heat transfer mechanisms are important to calculate the flow of heat and to design the most efficient flow path conforming to the process and deciding the required insulation for any given application. Variousapplications require the certain amount of heat transfer. And for this critical radius of insulation plays an important role. Following specific objectives were undertaken:

1) Understand the concept of critical thickness of insulation.

2) Graphically represent the variation of heat loss against critical radius.

3) Apply the concept of critical thickness of insulation to decide appropriate thickness.

4) Thickness of insulation for practical applications.

5) Develop expression for critical thickness of insulation in case of cylinder.

6) Solve a numerical problem based on the expression for critical thickness of insulation.

Marios M. Fyrillas et al, [1] addressed the problem of two-dimensional heat conduction in a solid slab embedded with a periodic array of isothermal strips. The surfaces of the slab are subjected to a convective heat transfer boundary condition with a uniform heat transfer coefficient. Similar to the concept of critical insulation radius, associated with cylindrical and spherical configurations, he showed that there exists a critical insulation thickness, associated with the slab, such that the total thermal resistance attains a minimum, i.e. a maximum heat transfer rate can be achieved. The findings of this work offer opportunities for improving the design of a broad range of engineering processes and products .SamanRashidi et al,[2] showed that flow-field and heat transfer around a cylinder embedded in a layer of homogenous porous media can be investigated numerically. The range of Reynolds and Darcy numbers are chosen to be 1-40 and $1 \times 10^{-8}-10 \times 10^{-1} 1$ respectively and used Volume averaged equations for modeling transport phenomena within the porous layer by applying conservation laws of mass, momentum and energy in the clear region. They carried out comprehensive parametric study such as effects of several parameters, such as porous layer thickness, permeability, Darcy and Reynolds numbers on flow-field and heat transfer characteristics.. Finally an optimization process is conducted in order to determine the optimal thickness and porosity of the porous layer resulting in the lowest heat transfer from the cylinder. The critical radius of insulation decreases with increasing Darcy number because the convective heat transfer coefficient increases with increase in Darcy number for porous material with low thermal conductivity.M.R. Kulkarni [3] showed that use of the critical radius for radial heat conduction in thermal insulation system has been widely reported in the literature. When it is desirable to increase heat dissipation in these systems, the critical radius can be used in a definitive manner to maximize the heat dissipation. However, if it is desirable to decrease heat gain or heat loss, the critical radius only serves as a necessary condition, but it is not sufficient. He addressed that for design issues of such thermal system, the crossover radius is utilized. The crossover radius is defined as a radius greater than the critical radius such that the heat transfer with the corresponding amount of insulating material is equal to that of the bare thermal system. Both cylindrical and spherical systems are considered.Incropera,Dewitt,,Holman,S, ukhatme,Bejan and Kakac [4-8] concluded that any addition of insulating material in a radial system will always increase the conduction resistance but it will also decrease the convection and radiation resistances. This happens because the increased or extended surface area allows for more convective and radiative heat transfer to take place. This peculiarity has been recognized and reported extensively.Incropera,Dewitt,,Holman[4,5] used conventional thermal network analysis to determine critical radius, $r_{\text {critical }}$, for the insulation and derived for cylindrical system $(r=k / h)$ and for spherical system $(r=2 k / h)$, where $\mathrm{k}$ is the thermal conductivity of the insulating material and $\mathrm{h}$ the convective heat transfer coefficient. [9] Sunan Huanget.al, studied on crossover radius and overcome this identified limitation by quantifying the crossover and critical radii of a transient cylindrical system, allowing novel conclusions to be drawn between the steady-state and transient scenarios. It was also identified that the cycle-average heat transfer rate can stabilize to a quasi-static value in response to transient heating . E.M. Sparrow et al[10], analyzed the two-dimensional (i.e. radial and circumferential) heat transfer and fluid flow problem for a fluid-carrying, insulated horizontal cylinder which loses heat to air by natural convection by solving the differential form of the conservation laws. The resulting conjugate problem encompassed conduction in the insulation layer and natural convection in the 
ambient air. A one-dimensional, radial heat flow model of the problem was also investigated in detail, and the circumferential-average natural convection heat transfer coefficients needed for its evaluation were respectively taken from the commonly used correlations of McAdams, Morgan, and Churchill and Chu. It was found that the correlation-related spread of the heat transfer results from the one-dimensional model was greater than the difference between the one- and two-dimensional results. The use of the Morgan correlation gave the most accurate set of one-dimensional heat transfer results (i.e. best agreement with the two-dimensional results).Maria B. Zaturska[11], investigated thermal stability of reacting masses of slab and cylindrical form, having parts of their surfaces insulated and the remainder offering no resistance to heat transferred; only symmetrically heated reactants were considered by assuming that the ratio of insulation size to slab width or cylindrical radius is small; also perturbation expansions are used to determine the critical Frank-Kamenetskii parameter as a series in terms of this ratio.

\section{METHODOLOGY AND EXPERIMENTATION.}

It is known that for any radial system there exists an optimal insulation thickness. This can be proved by the fact that there are competing effects when insulation is increased. The first effect is that the conduction resistance increases when adding insulation. The competing effect is that as insulation is added, the total surface area of the system increases, causing the convection resistance to decrease. Thus there must be an optimal insulation thickness that minimizes the overall heat loss. Calculation of critical radiius of insulating material on circular solid of conducting material is followed.

Consider a cylindrical pipe of outer radius $r_{l}$ which is heated and whose outer surface temperature $T_{1}$ is maintained constant. The pipe is now insulated with a material whose thermal conductivity is $k$ and outer radius is $r_{2}$. Heat is lost from the pipe to the surrounding medium by combined effect of conduction and convection. The rate of heat transfer from the insulated pipe to the surrounding air is measured by using temperature sensors like thermocouple. The value of $r_{2}$ at which heat transfer rate reach maximum is determined. Performing the differentiation and solving for $\mathrm{r}_{2}$ yields the critical radius of insulation for a circular body.

The critical radius of insulation is given by the following equation $r_{c}=(k / h)$. Above this critical radius, the heat flux decreases and below it, the heat flux increases as the fig.1below illustrates.

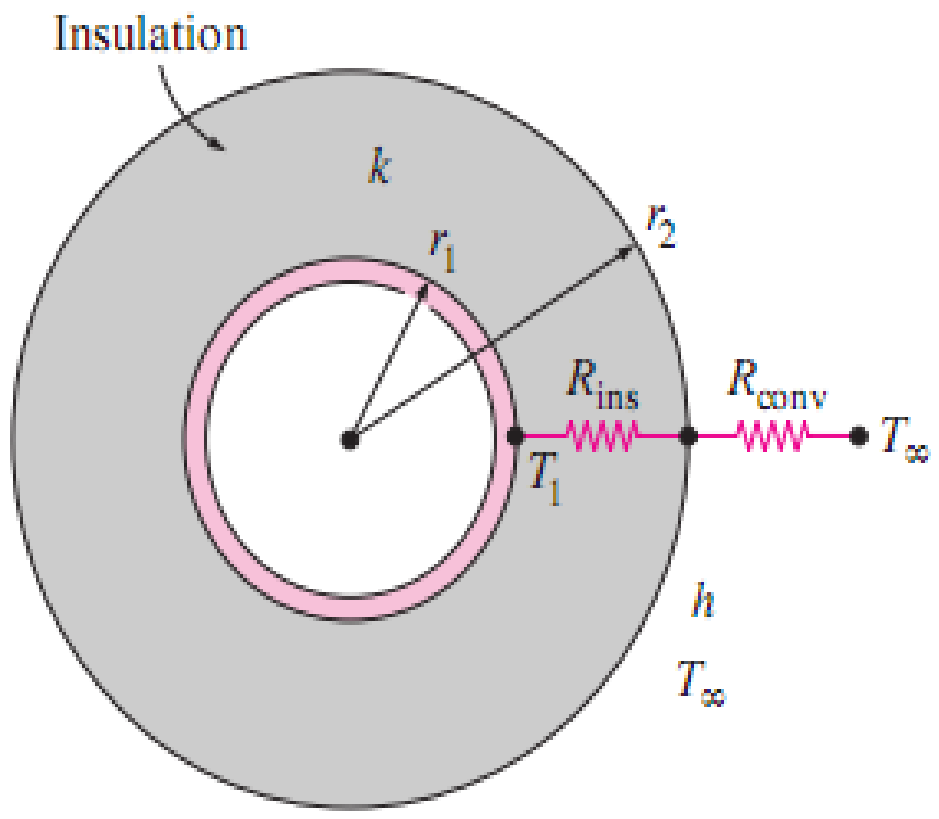

Fig. 1 critical Radius Of Insulating Material.

\section{ASSUMPTIONS:}

1) All air gaps are neglected.

2) Heat is assumed to be uniformly distributed

3) Convection between copper rod and the heater is neglected.

4) Radiations losses are neglected.

5) Clamps used for holding the insulated rod do not absorb any heat during the process and hence aren't considered in calculations. 


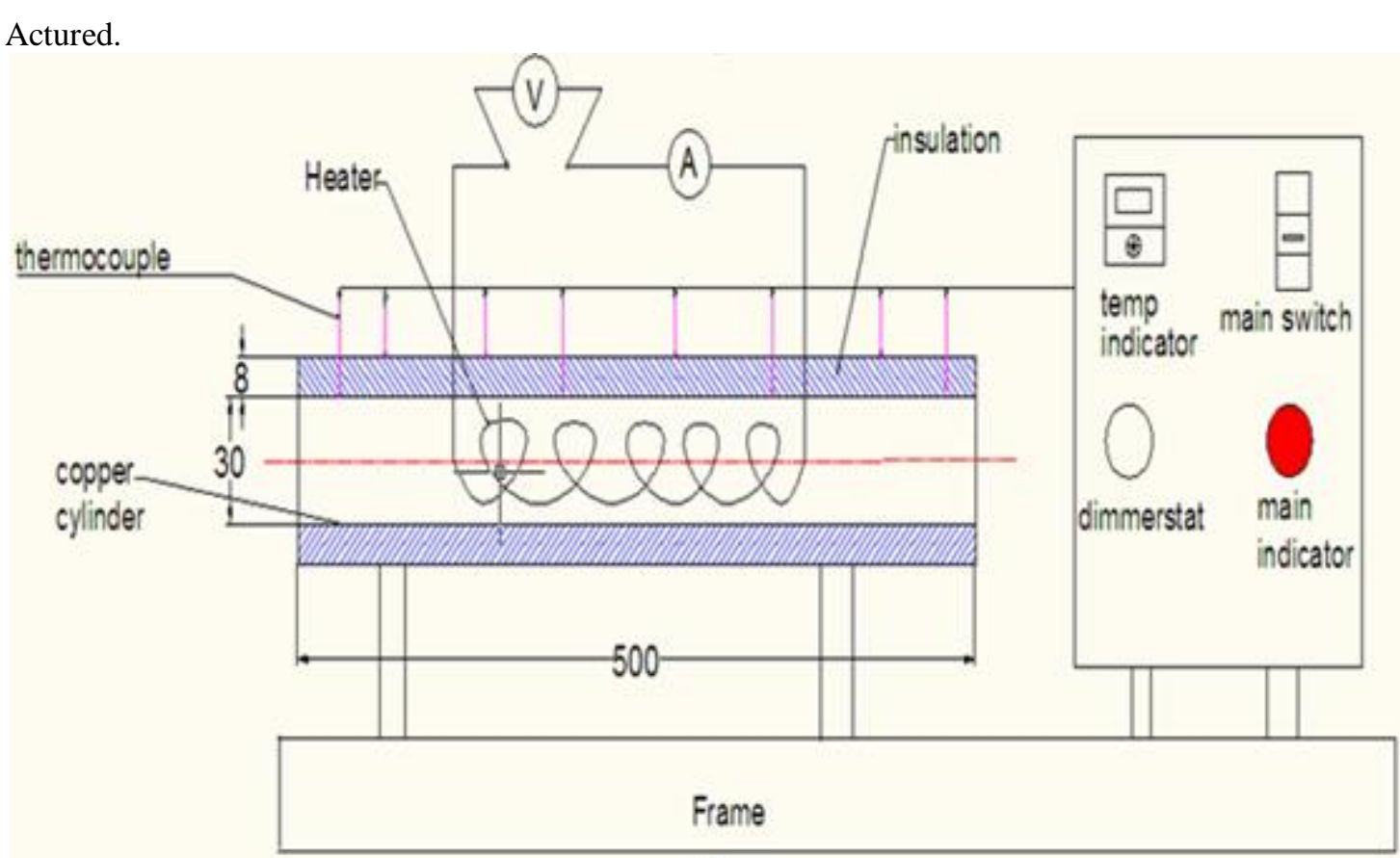

Fig.2.Setup Diagram.

Set up diagram( fig.2) consist of Frame, Thermocouple, Temperature Indicator, Voltmeter, Ammeter, Copper Rod, Resistive Heater, Main Switch, Electric Conductor Wire, Asbestos Insulation .Frame of mild steel by length $=600 \mathrm{~mm}$, Height $=600 \mathrm{~mm}$,Width $=300 \mathrm{~mm}$, is manufactured. Frame is used to supportother equipment/Control Panels(Thermocouple, Temperature Indicator, Voltmeter, Ammeter, Copper Rod, Resistive Heater, Main Switch.)

Supporting Frame is placed on the main frame to the support of Insulating Copper Rod as well as Resistive Heater is placed inside of copper Rod as shown in fig. 2.Resistive heater is used for heating of copper rod. Heater is direct connecting to the Dimmer stat.

Dimmer stat is used to increase or decrease Voltage, or adjust the voltage what is required for steady state condition. If voltage increases then more time consume for coming steady state condition or its decreases then it will come yearly in steady state condition.

No. of thermocouples are placed on surface of Copper Rod, because thermocouples sense the surface temperature of copper rod. Asbestos insulation is wounded outside surface of copper rod. Then thermocouples are placed outside surface of insulation. $\mathrm{K}$ typethermocouples are used to measure temperature because frequency of $\mathrm{k}$ type thermocouples is more high.

Temperature Indicator is used to indicate temperature at every position of thermocouple.

Selection Of Material-Copper [K=385W/mK],Asbestos [K=0.15W/mK]

Parametersused For Design

$\mathrm{L}=0.15 \mathrm{~m}$ for each section.

$\mathrm{r}_{1}=0.016 \mathrm{~m}$.

$\mathrm{T} \infty=27.5^{\circ} \mathrm{C}$.

(Properties of air at $1 \mathrm{~atm}$ pressure $\mathrm{T} \infty=27.5^{\circ} \mathrm{C}$ ).

$\rho=1.164 \mathrm{~kg} / \mathrm{m}^{3}$

$\mathrm{Cp}=1007 \mathrm{Jgg}^{-1} \mathrm{~K}^{-1}$

$\mathrm{K}_{1}=0.02588 \mathrm{~W} / \mathrm{m}^{-1} \mathrm{~K}^{-1}$

$\mu=1.872 * 10-5 \mathrm{kgm}^{-1} \mathrm{~s}^{-1}$.

$\mathrm{v}=1.608 * 10-5 \mathrm{~m}^{2} \mathrm{~s}^{-1}$.

$\operatorname{Pr}=0.7282)$.

$r_{2}=r 1+t(t=t h i c k n e s s$ of insulation).

Formulae:

$\mathrm{T}_{\mathrm{m}}=\frac{\mathrm{T}_{\mathrm{s}}+\mathrm{T}_{\infty}}{2}$

$\beta=\frac{1}{T_{m}}-------$

$\operatorname{RaD}=\frac{\left.\left(\mathrm{g} \beta(\mathrm{Ts}-\mathrm{T} \infty) \mathrm{D}^{3}\right) * \operatorname{Pr}\right)}{v^{2}}$ 


$$
\begin{aligned}
& \mathrm{Nu}=\frac{0.6+\left(0.387 * \mathrm{RaD}^{1 / 6}\right)}{\left[1+(0.559 / \mathrm{Pr})^{9 / 16}\right]^{8 / 27}}----- \\
& \mathrm{h}=\frac{\mathrm{K} * \mathrm{Nu}}{\mathrm{D}} \\
& \mathrm{Q}_{\text {conv }}=\mathrm{hA}_{\mathrm{s}}\left(\mathrm{T}_{\mathrm{s}}-\mathrm{T}_{\infty}\right) \text {.-------- } \\
& \mathrm{r}_{\mathrm{cr}}=\frac{\mathrm{k}}{\mathrm{h}} \\
& \mathrm{Q}=\frac{\mathrm{T}-\mathrm{T}_{\infty}}{\frac{\ln \frac{\mathrm{r}}{\mathrm{r}}}{2 \pi \mathrm{kL}}+\frac{1}{\mathrm{~h} 2 \pi \mathrm{r}_{2} \mathrm{~L}}}
\end{aligned}
$$

\section{RESISTANCE CALCULATION AND COMPARISON:}

Total resistance $=$ conductive resistance + convective resistance

$=\left[\ln \left(\mathrm{r}_{2} / \mathrm{r}_{1}\right) / 2 \pi \mathrm{kl}\right]+1 / 2 \pi \mathrm{rhL}$

Sample calculation for $22 \mathrm{~mm}$ outer radius

Hence $r_{1}=16 \mathrm{~mm}$

$$
\mathrm{r}_{2}=22 \mathrm{~mm}
$$

Hence total resistance $=[\ln (22 / 16) /(2 \pi(0.15 * 0.15)]+1 /(2 \pi(.022 * 6 * 0.15))$

$$
\begin{aligned}
& =2.526+8.038 \\
& =10.29073 \mathrm{~K} / \mathrm{W}
\end{aligned}
$$

Calculation of heat transfer rate by change in radius (Sample calculation)

1) Calculate the heat transfer rate for $R_{2}=22 \mathrm{~mm}$.

$$
\begin{array}{lll}
\mathrm{R}_{2}=22 \mathrm{~mm} . & \mathrm{R}_{1}=16 \mathrm{~mm} . & \mathrm{T}_{\mathrm{s}}=49.925^{\circ} \mathrm{C} \\
\mathrm{T}_{\infty}=27.5^{\circ} \mathrm{C} & \mathrm{L}=0.015 \mathrm{~m} &
\end{array}
$$

Heat transfer rate

$\mathrm{Q}_{2}=\frac{49.925-27.5}{\frac{\ln \frac{22}{16}}{2 \pi * 0.15 * 0.15}+\frac{1}{6 * 2 \pi * 0.022 * 0.6}}$

$$
\mathrm{Q}=\frac{\mathrm{T}-\mathrm{T}_{\infty}}{\frac{\ln \frac{\mathrm{r} 2}{\mathrm{r}_{1}}}{2 \pi \mathrm{kL}}+\frac{1}{\mathrm{~h} 2 \pi \mathrm{r}_{2} \mathrm{~L}}}
$$

$\mathrm{Q}_{2}=2.179173 \mathrm{~W}$

\begin{tabular}{|c|c|}
\hline Radius Of Insulation (mm) & Q-Heat Transfer Rate(W) \\
\hline 22 & 2.1792 \\
\hline 25 & 2.1921 \\
\hline 28 & 2.1827 \\
\hline 31 & 2.1604 \\
\hline
\end{tabular}

III. RESULTS AND DISCUSSION

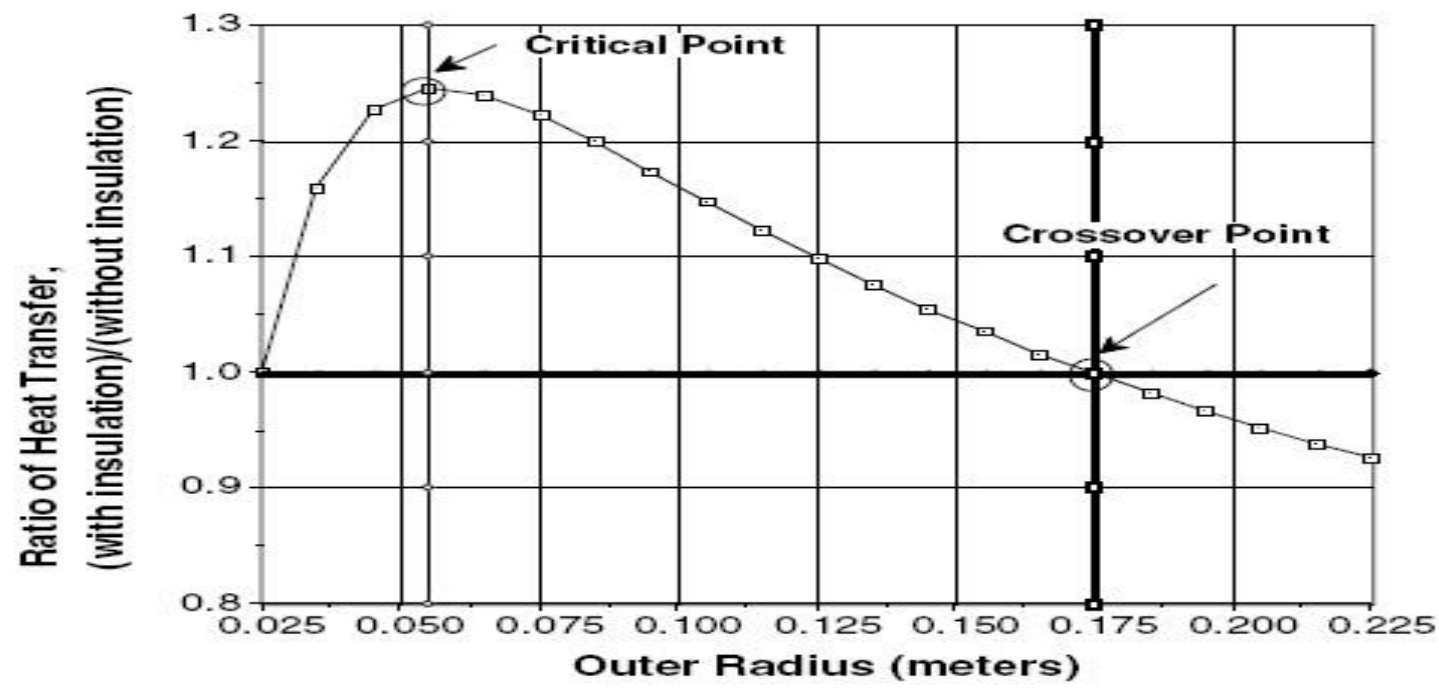

Fig. 3 Outer radius vs. Heat transfer 

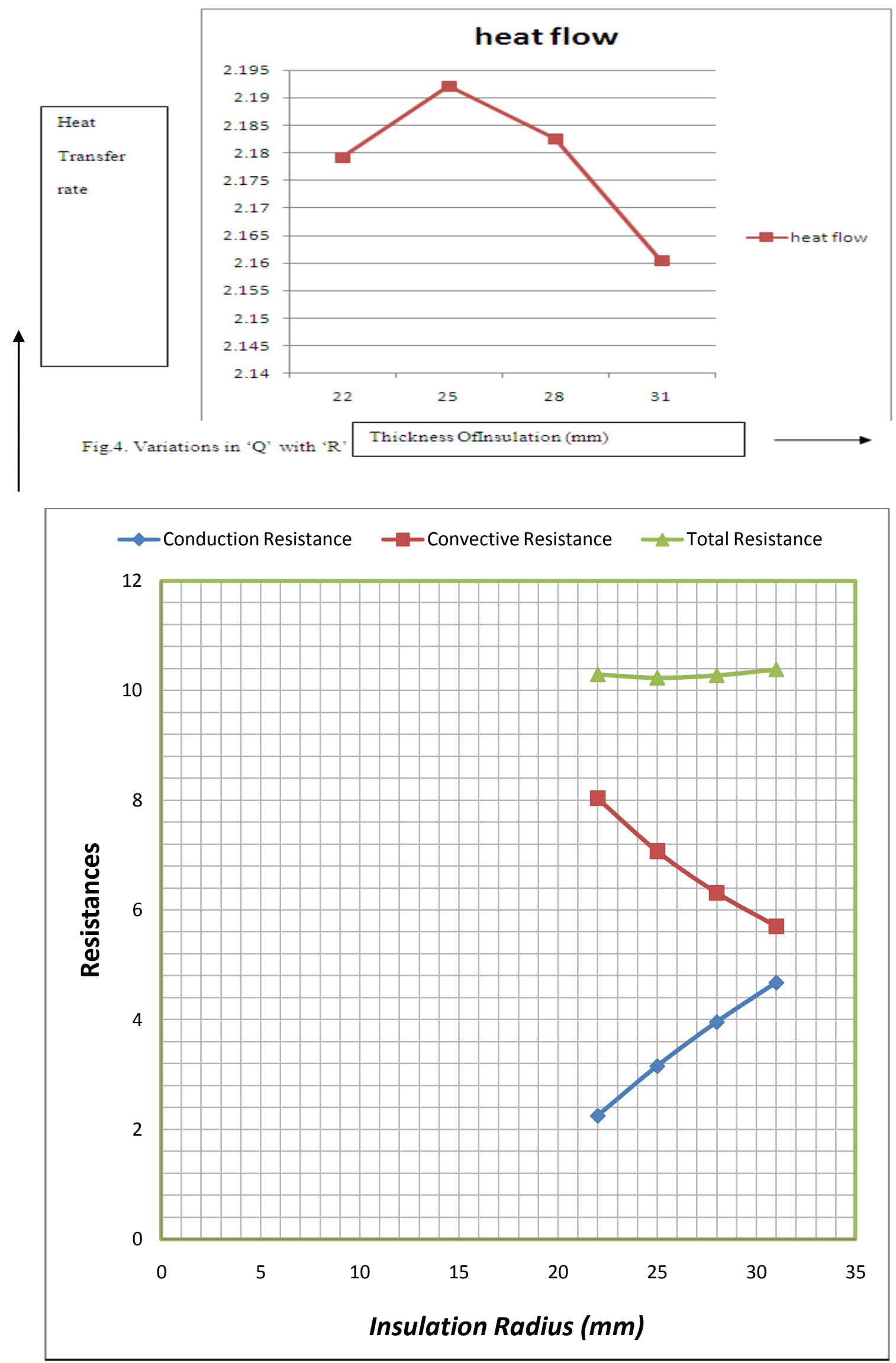

Fig.5. Variation of resistance with radius of insulation 
1. From fig. 3 ratio of heat transfer without insulation to with insulation goes on increasing with outer radius of insulation and reaches the maximum value at a point known as Critical Point.

2. Fig.4 shows heat transfer goes on increasing until the critical point, as the thickness of insulation increases further the heat transfer rates reduces.

3. Fig.5 shows convective resistance increases and convective resistance decreases as insulation radius increases, whereas total resistance remains almost constant.

\section{CONCLUSIONS}

1. With the help of this apparatus we can determine the critical radius of any insulating material by changing insulating material.

2. The same set up can be modified to determine the critical radius for different geometries. (eg. sphere)

3. By calculating heat transfer through bare radius system by considering all losses, we can calculate cross over radius by adding more and more insulating material beyond critical thickness.

4. Receive good critical point.

5. Noiseless and easy working operation.

6. Understood the concept of critical thickness of insulation and graphically represented the variation of heat loss against insulation thickness.

7. Apply the concept of critical thickness of insulation to decide appropriate thickness for practical applications.

8. Developed an expression for critical thickness if insulation in case of cylinder and solved numerical problem based on expression for critical thickness if insulation.

\section{REFERENCES}

[1] Marios M. Fyrillas et al, Howard A. Stone et al, Critical insulation thickness of a rectangular slab embedded with a periodic array of isothermal strips, International Journal of Heat and Mass Transfer 54 (2011) 180-185.

[2] SamanRashidi et al, Ali Tamayol et al, Mohammad SadeghValipour et al, NimaShokri et al.Fluid flow and forced convection heat transfer around a solid cylinderwrapped with a porous ring, International Journal of Heat and Mass Transfer 63 (2013) 91-100.

[3] M.R. Kulkarni,Critical radius for radial heat conduction: a necessary criterion but not always sufficient,Applied Thermal Engineering 24 (2004) 967-979.

[4] F.P. Incropera, D.P. DeWitt, Introduction to Heat Transfer, third ed., John Wiley Publishers, New York, 1996,pp. 93-99.

[5] J.P. Holman, Heat Transfer, eighth ed., McGraw-Hill Publishers, New York, 1997, pp. 38-39.

[6] S.P. Sukhatme, Heat Transfer, second ed., Orient Longman Publishers, Bombay, 1983, pp. 27-30.

[7] A Bejan, Heat Transfer, John Wiley Publishers, New York, 1993, pp. 42-45.

[8] S. Kakac, Y. Yener, Heat Conduction, third ed., Taylor \& Francis Publishers, Washington, DC, 1993, pp. 62-63.

[9] Sunan Huang et al, JaronieMohdJani et al, Martin Leary et al, Aleksandar Subic et al, The critical and crossover radii on transient heating, Applied Thermal Engineering 60 (2013) 325e334.

[10] E.M. Sparrow et al, S.S. Kangetal, Two-dimensional heat transfer and critical radius results for natural convection about an insulated horizontal cylinder Original Research Article, International Journal of Heat and Mass Transfer, Volume 28, Issue 11, November 1985, Pages 2049-2060.

[11] Maria B. Zaturska, Thermal explosion theory for partially insulated reactants Original Research Article Combustion and Flame, Volume 56, Issue 1, April 1984, Pages 97-103. 